\title{
Long-term changes of hydrogen-containing species in the stratosphere
}

\author{
M. Riese, J. U. Grooß, T. Feck, and S.Rohs
}

\section{ABSTRACT}

Understanding the $1 \%$ per year increase of stratospheric water vapour from 1954 to 2000 is a great challenge in atmospheric science. The increase is predominantly caused by longterm changes in transport of water vapour into the stratosphere and systematic increases of tropospheric methane levels. This paper gives a review on stratospheric water vapour changes for the 1980 and 2000 time period with emphasis on the contribution of methane oxidation. Predictions for 2050 indicate that likely increases of tropospheric methane levels will lead to an increase of upper stratospheric water vapour values of about $0.4 \mathrm{ppmv}$. A similar value is predicted as an upper limit of effects of a future hydrogen economy.

\section{Introduction}

The observed increase of stratospheric water vapour of about $1 \%$ per year in the second half of the last century (e. g. SPARC, 2000; Oltmans et al., 2000) has received considerable attention because of its impact on the radiation budget of the atmosphere. Forster and Shine [1999] modelled the temperature response to 1979 - 1997 changes in carbon dioxide, stratospheric ozone, and water vapour and found that water vapour increases of $1 \%$ per year enhance the radiative forcing of carbon dioxide alone by $40 \%$. Water vapour increases may also have significantly contributed to the observed cooling of the lower stratosphere. In addition to the cooling effect, increased water vapour concentrations lead to a more frequent generation of polar stratospheric clouds and enhanced ozone loss, and consequently, delay the expected recovery of the stratospheric ozone layer.

Long-term variations of water vapour are predominantly caused by changes in the influx of tropospheric water and changes in the in-situ water vapour production by methane oxidation. While changes in the water vapour influx remain a matter of debate, recent studies provided a clearer picture of the contribution of increased methane oxidation [e. g. Röckmann et al. 2004, Rohs et al., 2005]. This paper gives a review on the contribution of methane oxidation to water vapour changes in the 1980 to 2000 time period. In addition, predictions of stratospheric water vapour changes from 2000 to 2050 based on likely methane changes are compared to possible effects of a global hydrogen economy. 


\section{Water vapour in the stratosphere}

The extreme dryness of the stratosphere is a result of the Brewer-Dobson circulation (Brewer, 1949), wherein tropospheric air enters the stratosphere by crossing the cold tropical tropopause. Since freeze drying plays an important role, stratospheric water vapour is controlled to a large degree by the temperature field near the tropical tropopause. The socalled tropical tape recorder (Mote et al., 1996) demonstrates that the observed annual cycle of stratospheric water vapour is closely coupled to the annual cycle of the tropical tropopause temperature. Interannual anomalies of stratospheric water vapour with amplitudes of about 0.3 ppmv also show the coupling of stratospheric water vapour variability with tropical tropopause temperatures [Randel et al., 2004]. These anomalies exhibit an approximate 2years periodicity, which is predominantly influenced by QBO effects. They propagate into the stratosphere in analogy to the seasonal tape recorder. In general, water vapour mixing ratios of air parcel entering the stratosphere gradually increase by methane oxidation from their entry value of about 3.5 ppmv to more than 7.0 ppmv in the upper stratosphere (e. g. Engel et al., 1996], while (in the absence of changes in the water vapour influx) the quantity $\mathrm{H}_{2} \mathrm{O}+$ $2 \mathrm{CH}_{4}$ remains almost constant throughout the middle atmosphere. Structures and variability of water vapour and methane are therefore strongly coupled (e. g. Randel et al., 1999).

\section{Long-term variations of stratospheric water vapour and methane}

Long-term variations of water vapour

Long-term variations of water vapour and methane are of particular importance due to their influence on the radiation budget of the atmosphere and ozone-climate interactions [e. g. Shindell, 2001]. There is strong observational evidence that stratospheric water vapour may have increased as much as 2 ppmv between 1954 and 2000 [SPARC Assessment of Upper Tropospheric and Stratospheric Water Vapour (2000)]. A recent study of Rohs et al. [2005] indicates that less than one third of this positive increase can be explained by additional methane oxidation resulting from increased methane input from the troposphere. The remaining portion of the observed water vapour increase must therefore be attributed to increased water influx from the troposphere. While seasonal cycles and innterannual changes show good correlation with tropical tropopause temperatures, these long-term (decadal-scale) changes of stratospheric water vapour appear to be uncorrelated with corresponding tropopause temperature changes. A slow warming of the tropical tropopause would be a plausible explanation for the observed decadal-scale increase of stratospheric water vapour, however, the average temperature in this region is observed to decrease 
1 [Zhou et al., 2001] in the time period of interest. Understanding of the long-term water vapour

2 budget in the stratosphere is therefore a great challenge of atmospheric science and requires detailed understanding of transport and dehydration processes in the vicinity of the tropical tropopause [e. g. Dessler, 1998; Holton and Gettleman, 2001; Sherwood and Dessler, 2001; Fueglistaler et al, 2004, 2005]. Details of transport and dehydration processes have therefore been in the focus of recent tropical aircraft campaigns (e. g. SCOUT-O3).

The longest continuous record of lower stratospheric water vapour is provided by balloonborne frost point hygrometer measurements over Boulder, Colorado (40 N, $105 \mathrm{~W}$ ). The data show a statistically significant trend with an average increase between $1.0 \%$ and $1.3 \%$ per year at levels between 16 and $28 \mathrm{~km}$ [Oltmans et al., 2000]. This increase was confirmed by the SPARC assessment [2000] and an analysis of Rosenlof et al. [2001]. Randel et al. [2004] published detailed comparisons of this data set with HALOE (Halogen Occultation Experiment) satellite observations since 1992, which represent the best long-term global stratospheric water vapour data set. HALOE observations near Boulder are in reasonable agreement with the balloon data set in the altitude region from 17 to $22 \mathrm{~km}$ ( 82 to $46 \mathrm{hPa}$ ) for the time period 1992 to 1996. However, after 1997 the data sets diverge (see Figure 8 of Randel et al., 2004) with HALOE observations showing systematically lower water vapour measurements. In particular, HALOE data show persistent low values after 2001 (about 3.1 ppmv) suggesting the termination of the positive trend reported by SPARC [2000]. Despite some inconsistencies between the data sets, the relative decrease of lower stratospheric water vapour since 2000/01 is also resembled in the balloon observations (see Figure 8 of Randel et al., 2004). Moreover, HALOE observations are in remarkable agreement with POAM III (Polar Ozone and Aerosol Measurement III) observations concerning this feature [Randel et al., 2004].

Long-term variations of methane

Long-term trends of methane contribute to systematic long-term changes of water vapour in the stratosphere. About $60 \%$ of methane emissions are the result of anthropogenic activities such as fossil fuel production, cultivation of rice, stock farming and landfills [IPCC, 2001]. During the last decades, globally averaged tropospheric $\mathrm{CH}_{4}$ concentration increased significantly [e. g. Blake and Rowland, 1988; Khalil and Rasmussen, 1990]. The NOAA/CMDL Climate Monitoring and Diagnostic Laboratory network reports an increase of tropospheric $\mathrm{CH}_{4}$ mixing ratios from 1625 to 1751 ppbv for the time period from 1984 to 2002 with a decline in the $\mathrm{CH}_{4}$ increase rate being observed for the second half of this period [e. $\mathrm{g}$. 
1 methane can at maximum explain $50 \%$ of the $\mathrm{H}_{2} \mathrm{O}$ trend in the 1980 s and 1990s. This upper

2 limit estimate is based on the assumption that the additional stratospheric $\mathrm{CH}_{4}$ originating from the increased tropospheric $\mathrm{CH}_{4}$ is completely oxidised to water vapour in the stratosphere. A more realistic estimate was recently derived by Rohs et al. [2005] on the basis of long-term balloon measurements described in the next paragraph.

The most continuous long-term record of stratospheric methane and molecular hydrogen is provided by high-precision balloon measurements. From 1978 to 2003, measurements of numerous stratospheric trace gases were made by utilizing three neon-cooled cryogenic whole air samplers. Rohs et al. [2005] analyzed data from 32 flights of the cryosampler BONBON, which is operated in cooperation between the University of Frankfurt and Research Centre Jülich [see also Engel et al., 1998, Engel et al., 2002]. Most measurements were made at mid latitudes in Aire sur l'Adour and Gap in France (44 $\left.{ }^{\circ} \mathrm{N}\right)$ and since 1987 also at high latitudes in Kiruna, Sweden $\left(68^{\circ} \mathrm{N}\right)$. For a trend analysis, this data set was supplemented by two flights of the sampler CRYO MPI [Fabian et al., 1981] and 8 flights of the balloon-borne cryogenic sampler SAKURA [e. g. Nakazawa et al., 2002], which was launched from Sanriku Balloon Center of the Institute of Space and Astronautical Science, Japan $\left(39^{\circ} \mathrm{N}\right)$.

Figures $1 \mathrm{a}, \mathrm{b}$ show the altitude dependence of inferred methane increases for the time period from 1978 to 1998. A positive trend of the $\mathrm{CH}_{4}$ mixing ratio is found over the whole observational period for all altitude levels. The approximate altitudes of the data points (17, $23,26$, and $29 \mathrm{~km})$ are derived from $\mathrm{N}_{2} \mathrm{O}$ altitudes $(280,180,140$, and $80 \mathrm{ppmv})$, which were used in the trend analysis of Rohs et al. [2005]. The $\mathrm{CH}_{4}$ trend values shown in Figure 1 account for the age-of-air, which is calculated from correlations of between $\mathrm{N}_{2} \mathrm{O}$ and age-ofair [see Engel et al. (2002)]. The four altitude levels correspond to age-of-air values of 1.5, 4.4, 4.9 and 5.3 years, respectively. Using the $\mathrm{CH}_{4}$ trend values of Figures $1 \mathrm{a}, \mathrm{b}$ water vapour increases caused by additional methane oxidation can be calculated. Figure 1c shows the percentage contribution of these water vapour increases to the total water vapour increase of $1 \%$ per year obtained from the balloon-borne observations over Boulder. It is found that methane oxidation contributes less than $30 \%$ to the $1 \%$ per year increase of stratospheric water vapour between 1978 and 1998.

The longest continuous global data set for investigation of stratospheric methane changes is available from HALOE observations. Randel et al. [1999] analysed the 1992 to 1997 time period and found a gradually decreasing trend in methane mixing ratios, which even turns negative at altitudes above $30 \mathrm{~km}$. This finding suggests a more efficient methane oxidation 
1 in 1997 than in 1992 in the upper stratosphere. This is also consistent with the HALOE observation that the methane trend, which is gradually decreasing with altitude, is accompanied by a gradually increasing water vapour trend. A methane trend, which gradually decreases with altitude, is also evident in the balloon data presented in Figure 1. However, for the 1978 to 1998 time period the methane trend remains positive in the whole altitude range covered by the balloon observations (which were predominantly made at middle latitudes).

\section{Box model simulations}

Rosenlof (2002) suggested that changes in the residual circulation may lead to increased residence time of $\mathrm{CH}_{4}$ in the stratosphere and, in consequence, result in increases production of water vapour by more efficient methane oxidation. Röckmann et al. [2004] analysed three chemical mechanisms that must have led to more efficient methane oxidation in the stratosphere over the past decades: (1) increase of stratospheric chlorine levels as a result of anthropogenic CFC emissions, (2) thinning of the upper stratospheric ozone column as a result of chlorine chemistry and solar cycle effects. This thinning of the ozone column increases the $\mathrm{O}(1 \mathrm{D})$ production rate with consequences for methane oxidation, and (3) enhanced $\mathrm{OH}$ levels in the stratosphere as a result of increased input of tropospheric water vapour [about $0.5 \mathrm{ppmv} / \mathrm{decade}$. The relative importance of these processes for methane oxidation was analysed by Röckmann et al., [2004] utilising a box model, which consists of the chemistry module of the Chemical Lagrangian Model of the Stratosphere CLaMS [McKenna et al., 2002]. Simulations are made along a single air parcel that ascends from the tropical troposphere $(15 \mathrm{~N})$ to the stratopause $(1 \mathrm{hPa})$ within 4 years in accordance with the tape recorder described by Mote et al. [1996] and Rosenlof [2002]. For the 1980 to 1990 time period period, which is characterised by increasing tropospheric $\mathrm{CH}_{4}$ and $\mathrm{CFC}$ emissions, a substantial water vapour increase of 0.27 ppmv per decade was found in the upper stratosphere $(1 \mathrm{hPa})$. In the time period from 1992 to 1997, the combination of the three processes explains about $50 \%$ of the additional conversion of methane to water vapour observed by HALOE (see Figure 1 of Röckmann et al., 2004).

Figure 2 shows similar box model results for the 1980 to 2000 time period, which represents about the period of the balloon-borne water vapour and methane observations discussed in this paper. The 1980 to 2000 period was characterised by increasing atmospheric $\mathrm{CH}_{4}$ and CFC emissions, which result in a substantial water vapour increase of about $0.20 \mathrm{ppmv}$ per decade in the upper stratosphere $(1 \mathrm{hPa})$. This value is somewhat smaller than the 
1 in the 1990s. However, the enhancement of methane oxidation by increased chlorine levels and a thinning of the upper stratosphere ozone column is also important in the 1980 to 2000 time period (see Figure 2a). As a result, methane trends strongly decrease with altitude and even turn negative above $40 \mathrm{~km}$ in the box model simulation. The box model results cannot directly be compared to the balloon-borne measurements shown in Figure 1, which were predominantly made at middle latitudes. However, a decrease of the percentage methane trend with age-of-air (altitude), likely produced by increased chlorine levels and ozone column changes, is also evident in the balloon data of Figure 1.

\section{Future projections}

Röckmann et al. also presented future projections from box model calculations for the 2000 to 2050 time period (Figure 3 of their paper). For the reference case ("WMO Ab"), they used a $\mathrm{CH}_{4}$ baseline scenario after WMO (Table 12.2 in WMO, 1999) with tropospheric $\mathrm{CH}_{4}$ increases to 2000 ppbv in the year 2050 and stratospheric chlorine levels based on WMO halocarbon baseline scenario Ab (Table 4B-3 in WMO, 2003). In a second case ("WMO A2"), $\mathrm{CH}_{4}$ scenario A2 (Table 4B-3 in WMO, 2003) was used with an increase of tropospheric $\mathrm{CH}_{4}$ to $2562 \mathrm{ppbv}$. The results of the reference case "WMO Ab" are plotted in Figure $3 \mathrm{a}$ for $\mathrm{CH}_{4}$ changes only, and simulations accounting for additional CFC and ozone changes. Comparison to corresponding results of the 1980 to 2000 time period (Figure 2a) shows that the increase of water vapour resulting from methane oxidation is quite similar for both time periods. Increases per decade are, however, a factor 2.5 smaller than in the 1980 to 2000 time period. Furthermore, the decline of stratosphericchlorine leads to less effective methane oxidation.

Future predictions must also account for possible effects of a global hydrogen economy. Molecular hydrogen is an important trace gas in the atmosphere with a mixing ratio of about 0.5 ppmv. Rohs et al. [2005] find a very small increase of stratospheric $\mathrm{H}_{2}$ of the order of 0.3 $\%$ per year in the 1990s. The environmental impact of a future global hydrogen economy on the stratosphere was recently investigated by Tromp et al. [2003] and Schultz et al. [2003]. The main uncertainty of these studies concerns the leak rates for systems of $\mathrm{H}_{2}$ production, storage, and transportation. While the Tromp et al. adopt extremely high values of $10-20 \%$, Schultz et al. consider a loss rate of $10 \%$ as an upper limit. A $10 \%$ globally averaged leak rate and a hypothetical $50 \%$ replacement of today's fossil fuel combustion by hydrogen technology corresponds to a tropospheric $\mathrm{H}_{2}$ mixing ratio increase to 1.1 ppmv. Figure $3 \mathrm{~b}$ demonstrates that such an increase would double the additional stratospheric in-situ 
1 equally important. Methane oxidation in case "WMO A2" provides about two times larger 2 additional water vapour values than methane oxidation in case "WMO Ab" combined with possible additional contributions of a global hydrogen economy.

\section{Summary and Conclusions:}

Long-term variations of water vapour and methane in the stratosphere influence the radiation budget of the atmosphere as well as ozone-climate interactions. Variations of water vapour are predominantly caused by changes in the influx of tropospheric water and changes in the in-situ production by methane oxidation as a result of increased tropospheric methane levels. There is strong observational evidence that stratospheric water vapour increased by about 1 \% per year between 1954 and 2000 [e. g. SPARC, 2000]. Persistent low water vapour measurements of HALOE and POAM III indicate a termination of the positive trend after 2001 [e. g. Randel et al., 2004]. These observations point to changes in the transport of water vapour into the stratosphere. Overall, long-term (non-monotonic) variations of stratospheric water vapour caused by variations of the influx from the troposphere appear to be on the order of 1 ppmv.

Highly precise long-term balloon observations of stratospheric methane indicate that methane oxidation can only account for one third of the $1 \%$ per year increase of water vapour observed over Boulder, Colorado between 1980 and 2000 [see Oltmans et al., 2000]. According to box model simulations, the monotonic increase of upper stratospheric water vapour caused by methane oxidation is about $0.4 \mathrm{ppmv}$ for this time period. The simulations also demonstrate that the enhancement of methane oxidation by increased chlorine levels and a thinning of the upper stratosphere ozone column was rather important between 1980 and 1990 (and also visible in the balloon-borne methane observations). From 2000 to 2050, upper stratospheric water vapour is predicted to increase by $0.4 \mathrm{ppmv}$ on the basis of the $\mathrm{CH}_{4}$ baseline scenario after WMO (1999). Effects of a future global hydrogen economy may be equally important.

\section{Acknowledgements.}

We would like to thank the balloon teams for providing excellent data sets for the methane trend analysis. The financial support for the balloon observations (e.g. OFP, EASOE, SESAME, THESEO, and ENVISAT-Validation) by the German Ministry of Research and Technology (BMBF) and the European Commission is also gratefully acknowledged. 


\section{References:}

Blake, D. R., and Sherwood Rowland, F., Continuing worldwide increase in tropospheric methane, 1978-1987, Science, 239, 1129-1131, 1988.

Brewer, A. W., Evidence for a world circulation provided by the measurements of helium and water vapor distribution in the stratosphere, Quart. J. Roy. Meteor. Soc., 75, 351 - 363, 1949.

Dessler, A. E., A reeximination of the stratospheric fountain hypothesis, Geophys. Res. Lett., 25, $4165-4168,1998$.

Dlugokencky, E. J., Houweling, S., Bruhwiler, L., Masarie K. A., Lang, P. M., Miller, J. B., and Tans, P. P., Atmospheric methane levels off: Temporary pause or a new steady-state?, Geophys. Res. Lett., 30, 1992, doi:10.1029/2003GL018126, 2003.

Engel, A., Schiller, C,. Schmidt, U., Borchers, R., Ovarlez H., and Ovarlez, J. The total hydrogen budget in the Arctic winter stratosphere during the European Arctic Stratospheric Ozone Experiment, J. Geophys. Res,. 101, 14495-14504, 1996.

Engel, A., and Schmidt, U., Stratospheric trends of CFC-12 over the past two decades: Recent observational evidence of declining growth rates, Geophys. Res. Lett., 25, 33193322, 1998.

Engel, A., Strunk, M. Müller, M., Haase, H.-P., Poss, C., Levin, I., and Schmidt, U., The temporal development of total chlorine in the high latitude stratosphere based on reference distributions of mean age derived from CO2 and SF6, J. Geophys. Res., 107 (D12), 10.1029/2001JD000584, 2002.

Fabian, P., Borchers, R., Flentje, G., Matthews, W. A., Seiler, W., Giehl, H., Bunse, K., Müller, F., Schmidt, U., Volz, A., Khedim, A., and Johnen, F. J., The vertical distribution of stable trace gases at midlatitudes, J. Geophys. Res., 86, 5179 - 5184, 1981.

Forster, P. M. de F., and Shine, K. P., Stratospheric water vapour changes as a possible contributor to observed stratospheric cooling, Geophys. Res. Lett., 26, 3309-3312, 1999. 
1 Fueglistaler, S., H. Wernli, and T. Peter, Tropical troposphere-to-stratosphere transport

2 inferred from trajectory calculations, J. Geophys. Res., 109, D03108, 2004.

4 Fueglistaler, S., M. Bonazzola, P. H. Haynes, T. Peter, Stratospheric water vapor predicted 5 from the Lagrangian temperature history of air entering the stratosphere in the tropics, $J$. Geophys. Res., 110, D08107, 2005.

Holton, J. R., and A. Gettlemann, Horizontal transport and the dehydration of the stratosphere, Geophys. Res. Lett., 28, 2799 - 2802, 2001.

Intergovernmental Panel on Climate Change (IPCC), Climate Change 2001: The Scientific Basis, edited by J. T. Houghton et al., Cambridge University, Press, New York, 2001.

Khalil, M. A. K., and Rasmussen, R. A., Atmospheric Methane: Recent Global Trends, Environ. Sci. Technol., 24, 549-553, 1990.

Mc Kenna, D. S., J.-U. Grooß, G. Günther, P. Konopka, R. Müller, G. Carver, and Y. Sansano, A new Chemical Lagrangian Model of the Stratosphere (CLaMS): 2. Formulation of chemistry scheme and initialization, J. Geophys. Res., 107, doi:10.1029/2000JD000114, 2002.

Mote, P. W., K. H. Rosenlof, J. R. Holton, R. S. Harwood, and J. W. Waters, An atmospheric tape recorder: the imprint of tropical tropopause temperatures on stratospheric water vapor, J. Geophys. Res., 101, 3989 - 4006, 1996.

Nakazawa, T., Aoki, S., Kawamura, K., Saeki, T., Sugawara, S., Honda, H., Hashida, G., Morimoto, S., Yoshida, N., Toyoda, S., Makide, Y., and Shirai, T., Variations of stratospheric trace gases measured using a balloon-borne cryogenic sampler, Adv. Space Res., 30, 13491357, 2002.

Oltmans, S. J., Vomel, H., Hofmann, D. J., Rosenlof, K. H., and Kley, D., The increase in stratospheric water vapor from balloon-borne, frostpoint hygrometer measurements at Washington DC and Boulder, Colorado, Geophys. Res. Lett., 27, 3453-3456, 2000.

Randel, W. J., Wu, F., Russell III, J. M., and Waters, J., Space-time patterns of trends in stratospheric constituents derived from UARS measurements, J. Geophys. Res., 104, 3711- 
2 Randel, W. J., Wu, F., Oltmans, S. J., Rosenlof, K., and Nedoluha, G. E., Interannual

3 Changes of Stratospheric Water Vapor and Correlations with Tropical Tropopause

4 Temperatures, J. Atmos. Sci., 61, 2133-2148, 2004.

5

Röckmann, T., Grooß, J.-U., and Müller, R., The impact of anthropogenic chlorine emissions, stratospheric ozone change and chemical feedbacks on stratospheric water, Atmos. Chem. Phys., 4, 693-699, 2004.

Rohs, S., C. Schiller, M. Riese, A. Engel, U.Schmidt, T. Wetter, I. Levin, T. Nakazawa, A. Aoki, Long-term changes of methane and hydrogen in the stratosphere in the period 1978 2003, J. Geophys. Res., in print.

Rosenlof, K. H., Oltmans, S. J., Kley, D., Russell III, W. J., Chiou, E.-W., Chu, W. P., Johnson, D. G., Kelly, K. K., Michelsen, H. A., Nedoluha, G. E., Remsberg, E.E., Toon, G. C., and McCormick, M. P., Stratospheric water vapour increases over the past half-century, Geophys. Res. Lett., 28, 1195-1198, 2001.

Rosenlof, K. H., Transport changes inferred from HALOE water and methane measurements, J. Meteorol. Soc. Japan, 80, 831-848, 2002.

Rosenlof, K. H., How water enters the stratosphere, Science, 302, 1691-1692, 2003.

Schultz, M. G., Diehl, T., Brasseur, G. P., and Zittel, W., Air pollution and climate-forcing impacts of a global hydrogen economy, Science, 302, 624-627, 2003.

Shindell, D., Climate and ozone response to increased stratospheric water vapour, Geophys. Res. Lett., 28, 1551-1554, 2001.

Sherwood, S. C., and A. E. Dessler, A model for transport across the tropical tropopause, J. Atmos. Sci., 58, 765 - 779, 2001.

SPARC, Assessment of Upper Tropospheric and Stratospheric Water Vapour, SPARC report $N^{\circ} 2$, WMO/TD N¹043, 2000.

Tromp, T. K., Shia, R.-L., Eiler, J. M., and Yung, Y. L., Potential environmental impact of a hydrogen economy on the stratosphere, Science, 300, 1740-1742, 2003. 
2 WMO (World Meteorological Organisation), Scientific assessment of ozone depletion: 1998,

3 WMO global ozone research and monitoring project, Report No.44, 498, Geneva, 1999.

4

5 WMO (World Meteorological Organisation), Scientific assessment of ozone depletion: 2002,.

6 WMO global ozone research and monitoring project, Report No.47, 498, Geneva, 2003.

7

8 Zhou, X.L., M. A. Geller, and M. H. Zhang, The cooling trend of the tropical cold point 9 tropopause temperatures and its implications, J. Geophys. Res., 106, 1511-1522, 2001.

10

11

12

13

14

15

16

17

18

19

20

21

22

23

24

25

26

27

28

29

30

31

32

33

34

35

36

37 
Figure Legendes

2

a)

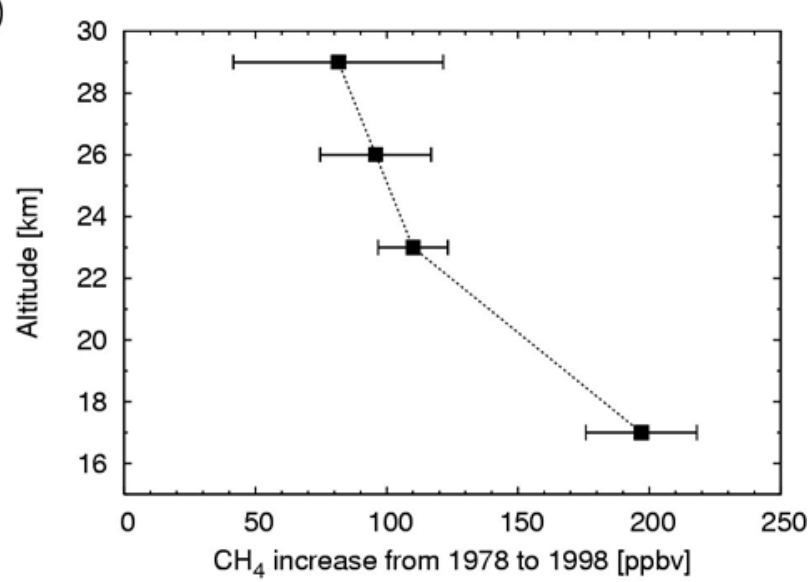

b)

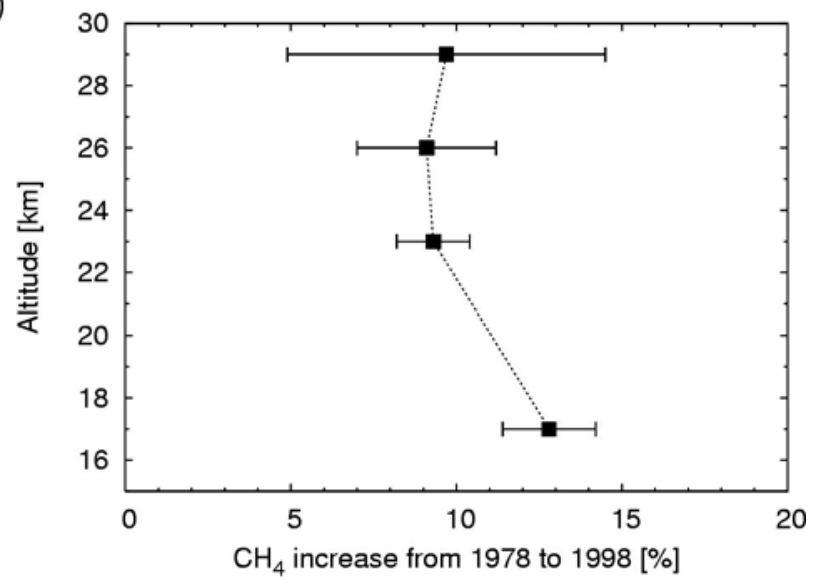

c)

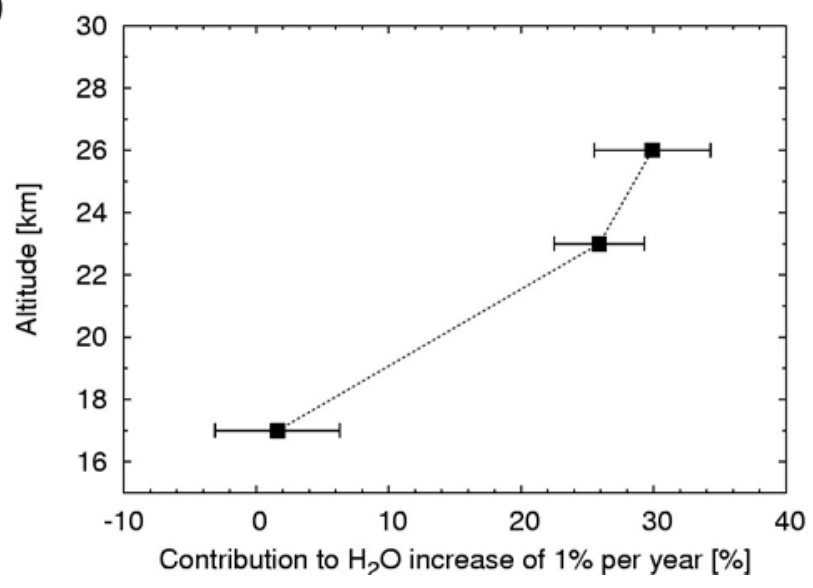

Figure 1: [a] Altitude dependence of methane increase [ppb] for the time period from 1978 to 1998 as derived from balloon observations. [b] Altitude dependence of methane increase [\%] for the time period from 1978 to 1998. [c] Relative percentage contribution of $\mathrm{CH}_{4}$ oxidation to the stratospheric

$10 \mathrm{H}_{2} \mathrm{O}$ increase of $1 \%$ per year. The contribution is presented for the altitude range of the water vapour trend values derived from balloon observations over Boulder (see Oltmans et al., 2000). 

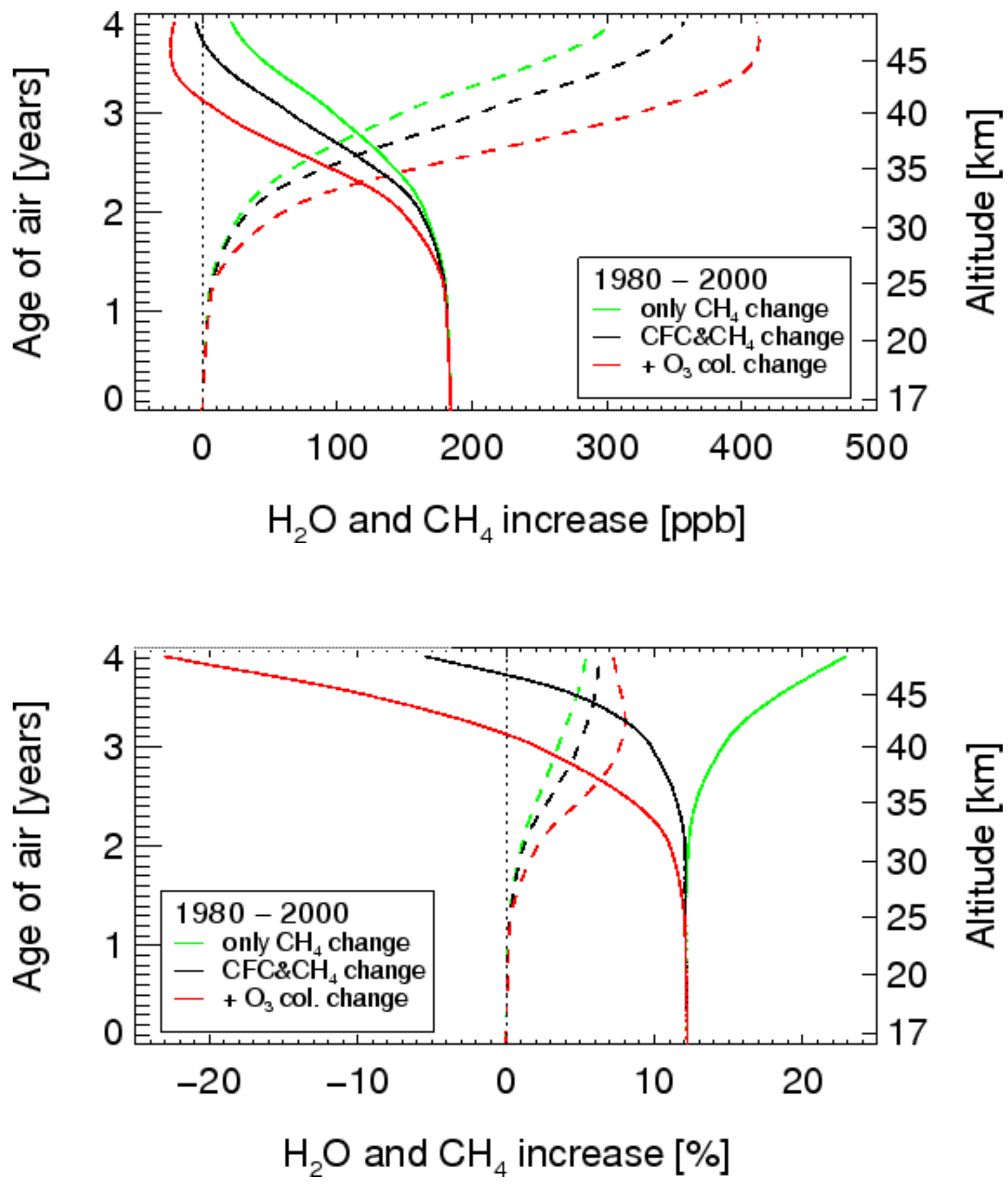

Figure 2: Results of box model calculations illustrating the effect of increasing $\mathrm{CH} 4$ and $\mathrm{CFC}$ levels in the atmosphere for the period 1980-2000. The calculations were performed for a single air parcel ascending at 15 degrees $\mathrm{N}$. The solid lines correspond to $\mathrm{CH} 4$ and the dashed lines correspond to $\mathrm{H} 2 \mathrm{O}$ increases. Shown is the change in ppb (a) and in percent (b) with respect to the year 1980. Results of simulations accounting only for the tropospheric $\mathrm{CH} 4$ trend are plotted green, black curves include the effect of the tropospheric CFC trend, red curves additionally include the effect of the thinning of the upper stratospheric ozone column. 

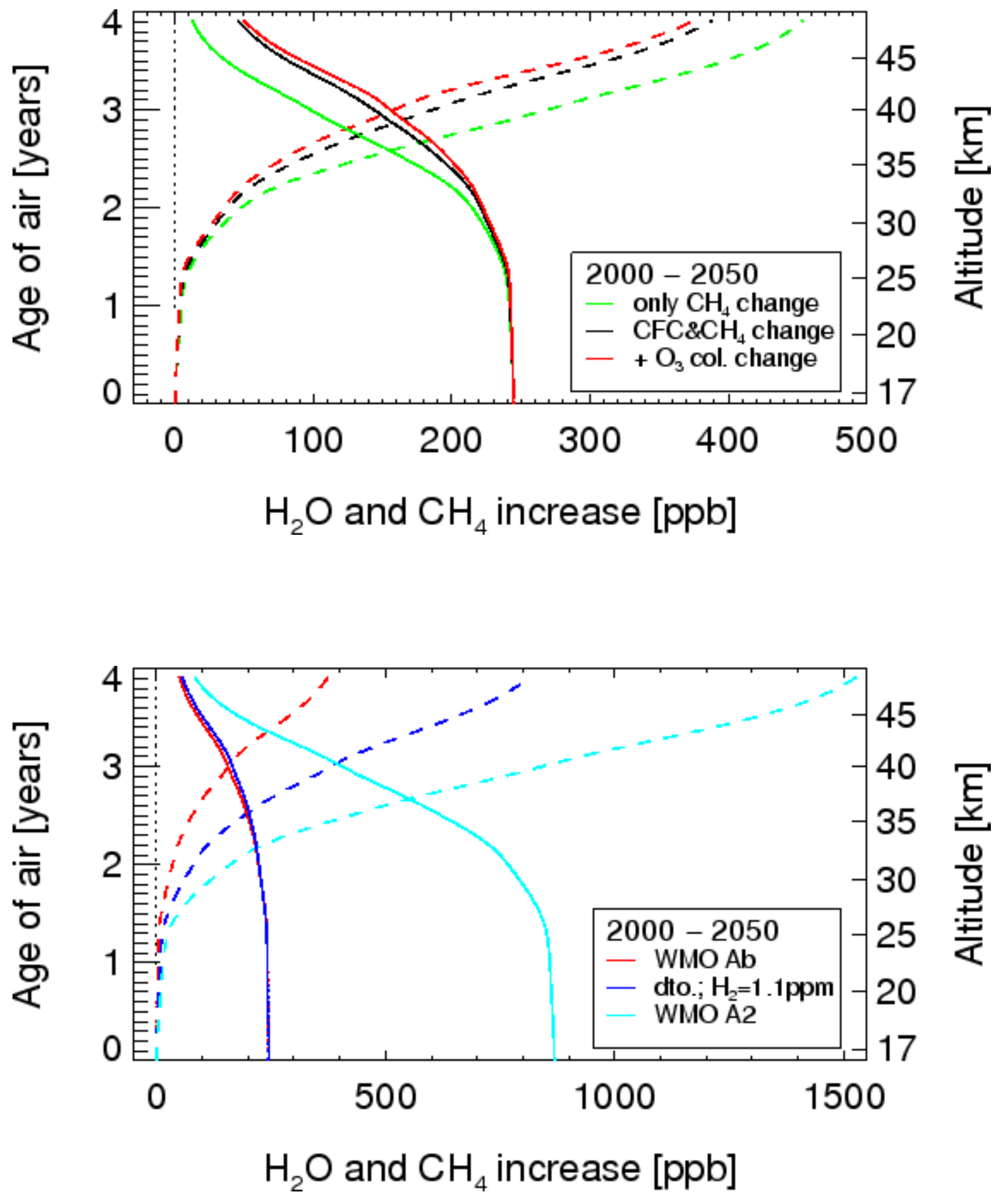

Figure 3: Future projections from box model calculations for the year 2050 with respect to the year 2000. The solid lines correspond to $\mathrm{CH} 4$ and the dashed lines correspond to $\mathrm{H} 2 \mathrm{O}$ increases. Panel (a) shows results for a $\mathrm{CH} 4$ baseline scenario (see text). Panel (b) shows the effect of different emission scenarios: red line (baseline) as in panel (a), the dark blue line corresponds to an additional increase of tropospheric $\mathrm{H} 2$ to $1.1 \mathrm{ppm}$, the light blue line corresponds to a larger $\mathrm{CH} 4$ increase according to the WMO scenario A2 (for more details see text). 